\title{
A representação do migrante clandestino no cinema contemporâneo: Efeitos e cenas de fronteira
}

The Representation of the Illegal Migrant in Contemporary Cinema: Border Scenarios and Effects

La représentation du migrant clandestin dans le cinéma contemporain: effets et scènes de frontière

\section{Fabrice Schurmans}

\section{OpenEdition}

\section{Journals}

Edição electrónica

URL: http://journals.openedition.org/rccs/5814

DOI: $10.4000 /$ rccs. 5814

ISSN: 2182-7435

\section{Editora}

Centro de Estudos Sociais da Universidade de Coimbra

Edição impressa

Data de publição: 1 Dezembro 2014

Paginação: 93-112

ISSN: 0254-1106

\section{Refêrencia eletrónica}

Fabrice Schurmans, «A representação do migrante clandestino no cinema contemporâneo: Efeitos e cenas de fronteira », Revista Crítica de Ciências Sociais [Online], 105 | 2014, colocado online no dia 03 dezembro 2014, criado a 19 abril 2019. URL : http://journals.openedition.org/rccs/5814 ; DOI $10.4000 /$ rccs.5814 


\section{FABRICE SCHURMANS}

\section{A representação do migrante clandestino no cinema contemporâneo: Efeitos e cenas de fronteira}

O presente artigo estuda um corpus de filmes que representam diversos percursos de migrantes clandestinos. A análise foca particularmente o lugar do clandestino na fronteira, entendida como lugar e metáfora. Após uma leitura crítica da noção de fronteira, descrevem-se as figuras recorrentes desta cinematografia: o clandestino que experimenta a fronteira, o homem ocidental em crise que se regenera no contacto com o Outro, a instância de receção que vê questionada a sua postura perante o sofrimento do/a migrante.

Palavras-chave: cinema; migrante clandestino; relações de fronteira; representação da fronteira.

Sabe-se que um certo cinema contemporâneo se tem apoderado da figura do migrante clandestino nas sociedades ocidentais, a ponto de quase originar um subgénero (Sotinel, 2009; Mandelbaum e Sotinel, 2011; Mandelbaum e Ridet, 2011). Qualquer que seja a sua origem, o migrante define-se neste cinema como ser fronteiriço, subordinado a múltiplos efeitos de fronteiras. Como o veremos mais à frente, estas não correspondem aos limites entre Estados ou às fronteiras externas da União Europeia. A fronteira que surge nestes filmes não está ligada a um contexto geográfico determinado por postes ou marcos, aparece antes como delimitação entre o cidadão dotado de uma existência legal e o sujeito desprovido de qualquer existência oficial. Este artigo trata justamente da natureza da representação da fronteira em alguns filmes contemporâneos. ${ }^{1}$

\footnotetext{
${ }^{1}$ O corpus aberto é o seguinte: Fast Food Nation (Linklater, 2006), Gran Torino (Eastwood, 2008), Lilya 4ever (Moodysson, 2002), Promised Land (Gitai, 2004), Le silence de Lorna (Dardenne, 2008), Transe (Villaverde, 2006), The Visitor (Mc Carthy, 2007) e Welcome (Lioret, 2009). Afastei filmes como Taken (Morel, 2008) por este transformar o migrante clandestino em paradigma do mal absoluto. Aqui, a fronteira não existe, pois nem o migrante, nem o cidadão ocidental em crise (por causa do rapto da filha por migrantes albaneses) chegam a partilhar um espaço de encontro, onde se possa criar uma sociabilidade alternativa.
} 
Esta questão da representação leva-nos a refletir sobre a natureza do tipo de análise utilizada. Se um filme de ficção, como um romance aliás, se inscreve numa sociedade determinada, se é determinado, em parte, por esta sociedade, seria errado considerá-lo um mero reflexo do social e analisá-lo consequentemente como um documento igual a tantos outros. Não se trata de estudar as configurações estéticas e de verificar posteriormente como estas dizem o real, pelo contrário, trata-se de perceber como a configuração estética se articula com uma questão social essencial, como, por exemplo, uma escala de plano ou a escolha de um determinado tipo de máquina de filmar traduzem algo do contexto social de referência.

É de relevo também, por um lado, a focalização quase exclusiva na figura do migrante clandestino e, por outro lado, a opção pela ficção e não pelo documentário. De facto, o migrante clandestino está longe de ser representativo de todo o fenómeno migratório. Como aponta o Relatório de Desenvolvimento Humano do Programa das Nações Unidas para o Desenvolvimento (PNUD) dedicado às Migrações (2009), trata-se de um fenómeno complexo caracterizado pela heterogeneidade, diversidade e dificuldade em agregar uma multiplicidade de experiências sob o único conceito de migração. No mesmo relatório, a migração clandestina constitui uma categoria entre várias, a par de outras como a migração económica, a migração resultante de um conflito, etc. No entanto, como evidencia o relatório em vários momentos, trata-se igualmente da migração de mais difícil abordagem (a clandestinidade da atividade explica a falta de dados fiáveis, a dificuldade de acesso às vítimas, assim como a dificuldade em distinguir certos atos voluntários de outros forçados) (PNUD, 2009: 23, 73-75). ${ }^{2}$ É justamente por causa destas características que os guionistas dos filmes sobre clandestinos optaram pela ficção e não pelo documentário, a primeira sendo mais apta a preencher os vazios e os silêncios, mais apta também a traduzir o sofrimento em personagens e assim comover, o que significa, neste preciso contexto, implicar o recetor.

Porém, a denominação de ficção coloca outro problema, pois o que caracteriza igualmente esta produção é a diversidade de abordagens

\footnotetext{
${ }^{2}$ De modo geral, é de notar a falta de dados claros relativamente aos fenómenos migratórios, o que leva o PNUD a afirmar que muitos dos aspetos do fenómeno migratório não são contemplados pelos governos do Norte quando estabelecem as suas políticas migratórias (PNUD, 2009: 31). Talvez isto explique por que razão, na França de Sarkozy, a luta contra a imigração ilegal e a transformação de um fenómeno social em problema político se fez em nome de valores e não de dados concretos (que apontam, aliás, para a ausência da suposta invasão) (Fassin, 2009: 22). Neste contexto, as representações do migrante clandestino em discursos de natureza diferente (político, mediático) suscitam em boa parte o medo no senso comum, medo que alimenta, em retorno, as ditas representações (Nasraoui, 2013: 93, 129).
} 
estéticas, desde o cinema da ilusão, com uma estrutura narrativa clássica (e.g. Welcome, The Visitor) até à prática de um cinema da alusão e da ousadia narrativa (e.g. Le silence de Lorna, Promised Land, Transe), o que ajuda a explicar, em parte, o menor impacto dos segundos junto do público. Talvez o êxito dos filmes do primeiro grupo também se deva à introdução no guião da figura de um cidadão ocidental em crise que vê a sua vida perturbada pela intrusão do migrante clandestino. Analisarei mais à frente os contornos desta figura recorrente.

\section{O migrante ilegal na ficção: sujeito fronteiriço}

Será preciso num primeiro momento tentar definir o que se tem tornado um conceito heuristicamente estimulante no campo das ciências sociais e humanas. Veremos a seguir que os percursos de algumas personagens de migrantes ilegais significam antes de mais pelo que experimentam na fronteira. Naturalmente, não se trata aqui de examinar em pormenor a complexidade do fenómeno fronteiriço, mas de evidenciar algumas das suas características, de esclarecer o caminho que levou do uso literal ao uso metafórico e de ver em que medida o conceito em questão pode ser útil numa análise fílmica.

Ultimamente, as ciências sociais e humanas têm revelado muito interesse pela fronteira, ou antes, pelo fenómeno fronteiriço (esta expressão tendo a vantagem de evidenciar o lado dinâmico e plural das relações na fronteira), numa perspetiva global. Com a desterritorialização de partes inteiras de atividades socioeconómicas, com a delegação de poder e de soberania do nível nacional para o nível europeu, tanto o conceito de fronteira como a fronteira enquanto fenómeno têm vindo a evoluir, ou, para ser mais preciso, a fronteira tem-se deslocado - dos marcos e dos postos fronteiriços aos centros fechados e outras zonas de trânsito para migrantes ilegais -, tem-se reconfigurado, ao mesmo tempo que tem penalizado cada vez mais a circulação de certos indivíduos (Makaremi, 2008; Sassen, 2002).

Em primeiro lugar, a fronteira, mesmo quando se quer e se afirma como estanque (penso aqui nos diversos muros em construção, desde os Estados Unidos e o México ao que Israel está a edificar na Cisjordânia), permanece um lugar de passagem, de contacto, um lugar onde paradoxalmente existe a possibilidade de uma ponte entre sujeitos, práticas sociais ou económicas, etc. É o que os organizadores afirmam na abertura de um número de Cultures \& Conflits, dedicado às fronteiras:

Certamente não será novidade considerar que as fronteiras fazem o mundo e que, nestas bordas dos Estados, se organizam lugares muito paradoxais, pois parecem 
negar a própria possibilidade da fronteira, criando pontes e continuidades onde frequentemente a política desejaria rutura e limite, socialmente estéreis, do exercício de uma soberania. (Bennafla e Peraldi, 2008) ${ }^{3}$

$\mathrm{O}$ que a maior parte dos estudos de tipo antropológico e sociológico deste número corroboram é, por um lado, o carácter global do fenómeno fronteiriço e, por outro lado, a transformação do papel da fronteira, nomeadamente no Norte. De facto, independentemente do contexto local, a fronteira contemporânea entra em hiato com os discursos oficiais tidos sobre ela (controlo, impermeabilidade, vigilância permanente), ou seja, não existe uma situação de fronteiras apreensível de modo simples, mas antes situações cuja complexidade as torna ao mesmo tempo de difícil acesso e estimulantes do ponto de vista teórico (Bennafla e Peraldi, 2008).

Por outro lado, houve no Norte uma transformação radical do papel da fronteira, que passou da marcação/afirmação da soberania nacional, com um forte cunho militar (origem etimológica da palavra), a um lugar de controlo, de contenção e de rejeição dos imigrantes clandestinos, com um forte cunho policial. O processo de unificação europeia e o seu corolário de abolição interna das fronteiras, ou melhor, da sua deslocação para leste e para sul, acelerou ainda mais este fenómeno. Trata-se de uma deslocação que foi acompanhada por um reforço tecnológico do controlo dos novos limites com o objetivo de construir uma separação absoluta (ibidem).

Independentemente do contexto, os discursos oficiais visam de facto construir a representação de uma fronteira estanque, controlada por meios de alta tecnologia, separação perfeita entre nós e os outros, estes sempre conotados de modo negativo (o imigrante ilegal, o bandido, a prostituta, etc.). No entanto, vários estudos apontam para a discrepância entre o discurso e as práticas observadas in loco. Esta situação manifestava-se claramente na fronteira entre a Áustria e a República Checa até 2007 (data da entrada deste último Estado no espaço Schengen), onde a primeira afirmava, nos seus discursos oficiais, controlar os fluxos da imigração ilegal graças à presença do Exército, assim como de aparelhos de alta tecnologia. Porém, um estudo empírico da fronteira como fenómeno revelou práticas onde o aleatório, o acaso e o

\footnotetext{
${ }^{3}$ É nitidamente este o caso da fronteira entre a Índia e o Bangladeche. O Estado Indiano tem construído um discurso social em torno da fronteira que enaltece a sua inviolabilidade, o seu total controlo, o que uma análise in loco contraria imediatamente: "A fronteira é permeável e acomoda-se. A prova perfeita de que a necessidade faz a lei e que a realidade do terreno se ri da política nacionalista e das identidades falsas que inventa." (Rush, 2012: 6). No entanto, justamente por causa do hiato entre discurso político e práticas sociais, a mesma fronteira não favorece a emancipação (a não ser a emancipação económica de alguns) mas antes a exploração, o contrabando e a violência.
} 
contexto desempenhavam um papel central (Darley, 2008). Os controlos eram efetuados de maneira mais ou menos estrita em função do momento (de dia ou de noite), da nacionalidade da pessoa controlada, do seu género, etc., ou seja, em função de uma série de elementos que tornavam a fronteira um lugar menos estanque do que afirmava o discurso oficial, levando a autora do estudo a concluir: "Parece que a situação geográfica à margem dos espaços fronteiriços autoriza os seus autores a distanciar-se das representações centrais da fronteira como lugar de controlo mecânico e fixo [...].” (ibidem).

Portanto, mesmo alvo de uma transformação física (a edificação de muros e de miradouros) e sujeita a sistemas panópticos de vigia, a fronteira continua um lugar dinâmico onde se desenvolvem práticas intrínsecas à sua condição de limite (limites entre Estados, mas também entre o legal e o ilegal, o lícito e o ilícito). O seguinte exemplo mostra que a fronteira é muito mais do que a simples demarcação oficial entre dois Estados: é um lugar instável, de contornos imprecisos, uma espécie de geografia íntima marcada pelos deslocamentos de seres humanos e mercadorias. Um dos paradigmas possíveis desta situação são os atores do narcotráfico na fronteira entre Ciudad Juarez (México) e El Paso (Estados-Unidos) (Guez, 2008), duas cidades que, vistas com a distância que permite o programa Google Earth, formam uma gigantesca conurbação separada pela famosa barreira entre ambos os Estados. Os sujeitos entrevistados por Guez estão envolvidos em diferentes graus no comércio ilícito de estupefacientes e vivem todos da/ /na fronteira, uma fronteira que a autora tenta pensar tendo em conta as suas interações com os territórios, as pessoas, os projetos que liga e põe em rede. Se o controlo da fronteira é essencial para as organizações criminosas (pois a simples passagem inflaciona diretamente o preço da mercadoria), ela também se transformou numa meta para os pequenos transportadores de droga, a promessa de uma vida diferente, um símbolo de esperança, o que significa que para eles a fronteira existe antes de ser avistada. De facto, a partir do momento em que decidiram levar droga em direção à fronteira, esses pequenos transportadores já transgrediram a "fronteira" entre o legal e o ilegal, que a fronteira com o seu arame farpado, os seus agentes da autoridade, a sua violência legal parece reificar. O que sobressai das entrevistas levadas a cabo por Guez é justamente a relação complexa, particular, quase íntima, que os sujeitos têm com a(s) fronteira(s) que precisam de transpor para viver:

O traçado desta fronteira está em movimento: parece mais uma gradação fluída entre o que se faz e o que não se faz, indissociável do contexto sociohistórico do momento em causa. Os estupefacientes a caminho dos mercados do Norte carregam marcas de 
todas estas passagens, e as marcas do seu comércio e da sua interdição estão presentes numa infinidade de lugares e de práticas na fronteira. (Guez, 2008) ${ }^{4}$

O que este exemplo, além de muitos outros, revela é certamente um fenómeno complexo, um fenómeno cuja descrição pode funcionar de forma heurística para um pensamento metafórico da "fronteira". Contudo, o que este exemplo revela igualmente é a fronteira como fonte de tensão e de violência. Dito por outras palavras, se, de facto, a fronteira pode ser pensada como lugar de inventividade, de resistência aos obstáculos colocados pela autoridade estatal, como potencial de atividades económicas alternativas e de oportunidades diversas, é devido ao seu carácter intrinsecamente dúbio, ao mesmo tempo lugar de expectativa e de desilusão, de bem-estar (para alguns) e de sofrimento (para muitos). Qualquer possibilidade de um pensamento da/na "fronteira" só o pode ser se tiver em conta este aspeto. Para ser mais preciso, não posso recorrer à "fronteira" como metáfora sem ter em conta a ambivalência do referente, ou ainda recuperar somente os seus aspetos positivos para contribuir para o esboço de um pensamento na e da "fronteira".

O conceito de fronteira será útil para interpretar os filmes do corpus, mas apenas se tivermos consciência de que, em determinados contextos, este conceito não tem qualquer conotação positiva. Gostaria de ilustrar este ponto fulcral com uma curta sequência do filme Transe (Villaverde, 2006) durante a qual um guarda fronteiriço alemão interroga um comerciante russo pelo intermédio de um tradutor (00:18:38 - 00:20:05). Claramente influenciada pela estética do documentário, a sequência é filmada através da janela suja de uma cabine na fronteira. A legibilidade da situação é absoluta, pois o local sugere uma espécie de gaiola de vidro onde nada escapa ao observador; tanto o espetador no espaço da ficção como o viajante no espaço referencial têm a possibilidade de presenciar este tipo de situação.

Nem a fronteira, nem a tradução aliás (outra noção utilizada de maneira metafórica pelas ciências sociais e humanas) podem ser aqui encaradas de

\footnotetext{
${ }^{4}$ Porém, o que faz falta na análise de Guez é o contexto económico para explicar a assimetria crescente entre os dois lados da fronteira. Por causa da liberalização total em certos setores-chave como o da agricultura (consequência direta do Tratado ALENA), o México viu a sua organização económico-social profundamente perturbada: dois milhões de hectares de terra em pousio, oito milhões de camponeses obrigados a emigrar para os Estados Unidos ou ainda, em 2007, importação de 1,5 milhões de dólares em comida e emigração de trinta camponeses... por hora! No mesmo tempo, os Estados Unidos aumentavam os subsídios para os seus próprios agricultores (em 2002, os apoios aos produtores de milho eram dez vezes superiores ao orçamento do Ministério mexicano para a agricultura) e impunham, em violação dos termos do Tratado, restrições à importação de alguns produtos agrícolas (Vigna, 2008, 2009).
} 
maneira positiva. A fronteira é agora a fronteira externa da União Europeia, onde o que vem do Leste é visto com desconfiança. Ali, não se traduz para ir ao encontro do outro, mas porque se desconfia dele. Neste "entre-lugar", pouco importa a identidade do indivíduo em questão, este nem chega ao estatuto de personagem (não desempenha papel nenhum na estrutura geral do filme). Talvez, no seu anonimato, seja ele a metáfora do que se vive diariamente naquela fronteira. Em contrapartida, a realizadora mostra como, para as máfias, as fronteiras oficiais não constituem obstáculo nenhum, passam-nas à vontade, fluem de um país para o outro com seres humanos transformados em mercadoria. Noutra sequência (01:02:40 - 01:05:30), Sonia é vendida pelo seu raptor russo a um proxeneta italiano. Este observa-a como os compradores observavam os escravos nas colónias. Neste contexto, a tradução nem é necessária: o "pidgin English" serve perfeitamente e revela-se uma metáfora desta passagem de Sonia de um dono ao outro (o inglês é necessário como é necessária a "mercadoria" humana).

O que começa a emergir neste ponto é a ambiguidade e a ambivalência da noção de fronteira, o que explica, em parte, o seu êxito junto de ensaístas contemporâneos como Ribeiro (2001) ou Santos (2000). Existe claramente um uso metafórico aqui mas que no entanto, em função dos objetivos de cada um, remete para uma pluralidade de significados que às vezes se sobrepõem, e às vezes não. Apesar das diferenças, os dois autores encaram a "fronteira" como um lugar simbólico, uma espécie de heterotopia, ou seja, uma deslocação dentro da própria cultura do centro para as margens, a partir da qual é possível olhar de outra maneira a experiência humana, assim como as suas representações. Se Ribeiro pensa a "fronteira" a partir de representações literárias, ensaísticas, filosóficas, Santos, por sua vez, vê sobretudo a "fronteira" - na sua articulação com o Barroco e o Sul -, como um lugar favorecendo a emancipação individual.

Resumidamente, na sua procura de caminhos que levem à consolidação do paradigma emergente, Santos depara-se com um problema importante: se o paradigma em questão ainda não vigora, não é por ser incompleto ou atravessado por tensões (isto o sociólogo aceita e até defende), mas por a subjetividade vigente ter dificuldade não só em entender mas, mais grave, em desejar a emergência de um paradigma diferente do conhecido ou do que se julga conhecer. Daí a necessidade de pensar uma subjetividade outra, ela própria emergente, e, por enquanto, sediada numa utopia.

De facto, num momento de transição tão complicado onde só se conhece bem o paradigma vigente e onde o paradigma emergente está ainda por dar a (re)conhecer, é preciso uma subjetividade "suficientemente apta para compreender e querer a transição paradigmática”, uma subjetividade 
que transforme o medo, a inquietação perante o futuro em "energia emancipatória" (Santos, 2000: 321). Esta subjetividade é tanto mais difícil de desenvolver por implicar um sentido ético diferente (deve prestar uma atenção constante às consequências dos seus atos para a sociedade e o seu futuro) e por não se poder socorrer das experiências e dos discursos do passado, ou então das experiências e dos discursos que foram silenciados pela memória oficial. Esta situação pressupõe um distanciamento (o que implica também uma deslocação epistemológica do centro para as margens) relativamente ao cânone em torno do qual se fundamentou, e cristalizou, a nossa modernidade (ibidem).

Esta rápida contextualização permite apreender mais facilmente o papel da "fronteira" na reflexão de Santos sobre a subjetividade emergente. $\mathrm{Na}$ perspetiva utopista que caracteriza parte do seu percurso teórico, imagina a subjetividade em questão fundamentada em três topoi, outras tantas metáforas, entre os quais o da "fronteira".

Santos começa por conotar a "fronteira" de maneira positiva e entende enriquecer o leque das suas conotações, ou para dizê-lo por outras palavras, elaborar a sua própria metáfora de "fronteira", socorrendo-se do que julga ser um dos paradigmas possíveis da vida na fronteira: a fronteira do Oeste nos Estados-Unidos. De uma obra de historiadores americanos que descreve o fenómeno fronteiriço em questão retém o seu potencial heurístico, ou seja, seleciona algumas das características descritas em função do seu objetivo: "construir o tipo-ideal de sociabilidade de fronteira". Voltará a este ponto mais à frente ao dizer que o que interessa é a "fenomenologia geral da vida de fronteira", uma vida antes de mais marcada pela "instabilidade, a transitoriedade e precariedade da vida social" (ibidem: 325 ).

Ora, um dos problemas que acarreta o uso metafórico de um conceito - neste caso a elaboração metafórica seria mais apropriada - é que dificilmente se pode fazer tábula rasa do(s) sentido(s) próprios do significante e das conotações, positivas como negativas, associadas ao referente. Ribeiro sublinhou justamente que o conceito concebido como utopia traz problemas, pois, como resultado de uma construção social, a "fronteira" tanto pode ser o lugar da hibridação, de uma nova identidade, como um lugar de sofrimento e de exclusão. É um dos problemas que coloca um conceito flutuante, polissémico: por um lado é estimulante, aberto, por outro, produz ambiguidades e contradições (Ribeiro, 2001: 471-473).

Se, por um lado, o pensamento de/na fronteira se revela muito útil para ler e interpretar os filmes em estudo, a referência à frontier land como lugar para pensar a subjetividade emergente não deixa de colocar reservas. Entre os autores que mais pensaram as "fronteiras" induzidas pela globalização 
hegemónica, gostaria de destacar Zygmunt Bauman $(2004,2007)$ por este fazer críticas acérrimas à vida na "fronteira", bem como por ser um intelectual que, à semelhança de Chomsky, radica o seu pensamento numa recusa da teoria pura. Como é sabido, no âmago do seu pensamento reside a ideia de que, durante séculos, o Norte conseguiu despejar o seu "lixo humano" em territórios alheios. Com as independências sucessivas das colónias e a subjugação desses territórios à modernidade (no sentido de construção de ordens sociopolíticas e de progresso económico), esse mesmo Norte não só teve de lidar com o "lixo" doméstico como com o "lixo" importado das ex-colónias.

Os desempregados, os novos pobres, os refugiados, filhos de imigrantes da segunda e até da terceira geração, entre outros, amontoam-se nas cidades do Norte e este, como modo de proteção, abdicou da "reciclagem" para edificar barreiras e "fronteiras". Os novos guetos são locais para onde são enviados os "sem função", os redundantes, aqueles para quem a sociedade não encontra uso económico ou político. Com o desmantelamento do Estado-Providência, os guetos deixaram de funcionar como tampão de proteção para os excluídos, perderam qualquer aspeto positivo para se tornarem simplesmente maquinaria da social relegation, ou seja, uma espécie de "lixeira" onde se coloca o que é considerado perigoso e inútil. Em cidades como Paris, existem bairros que começam a ser tratados como autênticas prisões (dificuldade de acesso por meios de transporte público, postos de controlo, rusgas), ao passo que a própria prisão evolui em sentido análogo: já não pretende reeducar nem ressocializar, mas manter o controlo sobre o perigo que representa o buman waste. Ainda segundo Bauman, há assim uma clara correlação entre, por um lado, a renúncia do Estado a exercer a sua função reguladora social e económica e, por outro, a promoção de uma política securitária, o que tem como principal consequência a criminalização de muitos problemas sociais e a segregação dos redundantes em espaços mais ou menos estanques (bairros periféricos, prisões, centros fechados para imigrantes).

É neste contexto que Bauman aproxima as novas "fronteiras" do que acontecia na frontier. Encara a realidade social contemporânea como frontier land semelhante à frontier do Oeste Norte-americano no século XIX, onde a ausência de leis e normas beneficiava os barões do gado e os bandidos, que para Bauman têm o seu equivalente atual nas multinacionais e nos grupos terroristas, ambos responsáveis pela produção de "lixo humano", os primeiros no ramo do progresso económico e os segundos no ramo da "criação destrutiva da ordem". Nesta "fronteira", são óbvios os danos colaterais em vidas humanas causados pelos modernos barões do gado e por outros bandidos. Entre as consequências, Bauman destaca: a vida 
na "fronteira" como fonte de grande ansiedade, de medo (se a ameaça é real ou fantasiada é menos relevante neste contexto do que a realidade do medo), de instabilidade; a vida na "fronteira" como dissolução da confiança entre indivíduos e a sua substituição pela desconfiança generalizada; a "fronteira" como geradora de exclusão dos indesejados e de obsessão pela segurança entre os que vivem dentro. Recorrer a um autor como Bauman, cuja biografia evidencia uma larga e difícil experiência de várias "fronteiras", talvez obrigue a matizar o pensamento utópico de Santos com um toque de trágico, pois, para muitos "redundantes" ou condenados do planeta, as "fronteiras" determinam, em grande parte e sem celebração possível, o curso das suas vidas.

As personagens de migrantes ilegais do corpus do presente estudo correspondem bastante bem ao que Bauman diz da vida na fronteira. Sylvia e Raul, os migrantes mexicanos em Fast Food Nation, Lorna, a migrante albanesa em Le silence de Lorna, Sonia, a migrante russa em Transe, Tarek, o migrante sírio em The Visitor, Diana, a migrante estoniana de etnia russa em Promised Land ou ainda Bilal, oriundo do Curdistão iraquiano, em Welcome, experimentam constantemente os efeitos de uma vida na fronteira. Independentemente dos seus projetos de vida e da sua origem, o seu estatuto (migrante clandestino) assim como o seu lugar na fronteira transformam-nos em algo muito semelhante ao buman waste de Bauman. Nestes filmes, o migrante só existe enquanto mercadoria cujo valor de uso se mede pela sua capacidade de trabalho. Aliás, só vale enquanto dura a possibilidade de explorar o seu corpo. Neste contexto, não será por acaso que quase todos os filmes do corpus contêm uma sequência evidenciando o corpo esgotado ou ferido do migrante, pois é naquele momento que melhor transparece o seu estatuto de mercadoria descartável. ${ }^{5}$

A partir do momento em que as personagens pagam um intermediário, ou seja, a partir do momento em que mesmo longe da reificação material da fronteira tendem para esta, o seu percurso biográfico anterior, a narração do que foram antes da transação desaparece do guião. Perdem em parte o controlo do seu percurso, até porque dependem de um passador a par da rota para a fronteira. A partir de aí, a sua autonomia é reduzida (Lorna, Sylvia, Carlos, Tarek, Bilal) ou inexistente (Sonia, Diana) e a sua transformação em mercadoria quase absoluta.

\footnotetext{
${ }^{5} \mathrm{Na}$ sua biografia do migrante clandestino, Nasraoui insiste igualmente no corpo enfraquecido, doente, do clandestino, um corpo sem lar: "É em casa que se curam os sofrimentos e as deceções, que se regeneram as potencialidades e que se coloca um bálsamo nas feridas provocadas pela vida exterior. O migrante está exposto ao ar livre: não consegue esconder nem o seu corpo, nem os órgãos íntimos, nem os sofrimentos, faz as necessidades à vista de todos.” (Nasraoui, 2013: 208).
} 
Talvez os filmes que representam os percursos das mulheres destinadas à prostituição clandestina sejam os que melhor conseguem retratar a súbita transformação de um sujeito em mercadoria. Assim, em Promised Land, a sequência de abertura (00:00:00 - 00:09:35) mostra um grupo de mulheres russófonas a serem levadas por um grupo de beduínos no deserto do Sinai em direção à fronteira israelita. Esta não constitui obstáculo nenhum para o grupo que a perpassa apesar da sua militarização massiva. A presença das mulheres na fronteira é concomitante com a sua mercadorização absoluta, pois são a seguir vendidas numa espécie de leilão assaz semelhante ao que acontecia aos escravos e num inglês pidgin parecido com o utilizado pelos proxenetas em Transe. Nesta longa sequência da venda (00:12:48 - 00:22:08), o estado de partes do corpo (seios, nádegas, boca) indica o valor da mercadoria. Aqui não existem, porque não interessam na transação, nomes nem biografias, o anonimato dos corpos reforçando até o seu carácter de mercadoria. O vocabulário utilizado pelos diversos indivíduos envolvidos no tráfico (beduínos, palestinianos, israelitas de várias origens geográficas) remete para esta metamorfose; carga, lote, mercadoria são tantas palavras que designam literalmente, ou seja, sem figura de retórica, o que as mulheres são do seu ponto de vista.

O filme de Gitai evidencia fronteiras materiais porosas, mesmo as que, para a população palestiniana, são quase intransponíveis. Assim, os passadores levam um grupo de mulheres para Ramallah sem problema, o checkpoint do exército israelita não sendo para eles um obstáculo. Aqui a fronteira oficialmente hermética, barreira que deveria garantir a segurança do Estado israelita e dos seus cidadãos, é representada como permeável, ineficaz, lugar de contrabando e de exploração. Nisto, Promised Land retrata fielmente o hiato entre o discurso oficial tido sobre a fronteira e a fronteira como fenómeno dinâmico e criminógeno. O contexto geográfico neste ponto importa pouco - México-Estado Unidos, Israel-Palestina, Índia-Bangladeche - pois basta existir uma relação desequilibrada de poder entre ambos os lados, um desenvolvimento económico assimétrico entre dois países para facilitar a transformação da fronteira em lugar de corrupção, de violência e de alienação, ${ }^{6}$ com a emancipação económica e social a ser associada sobretudo aos contrabandistas e guarda-fronteiras.

No entanto, a passagem da fronteira material não significa para a personagem do/a migrante clandestino o fim da sua situação de ser fronteiriço.

\footnotetext{
${ }^{6}$ Facto sublinhado por Sassen na sua reflexão sobre a ligação entre migrações e globalização neoliberal: "Na verdade, à medida que os países de destino têm vindo a reprimir as entradas e a semimilitarizar uma porção cada vez maior das suas fronteiras, tem-se verificado um aumento acentuado deste tráfico ilegal de pessoas." (Sassen, 2002: 41).
} 
Em Fast Food Nation, o grupo de mexicanos que entra nos Estados-Unidos e encontra trabalho num talho industrial não perde o seu estatuto de corpo-mercadoria. O filme de Linklater associa intimamente o/a migrante enquanto ser fronteiriço por essência com o modo de funcionamento da economia neoliberal que, em grande parte, precisa da fronteira para garantir os seus lucros. O filme entrelaça os percursos de um grupo de migrantes mexicanos com a investigação levada a cabo por Don Anderson, quadro na multinacional onde trabalham os primeiros. A montagem aponta para o papel central do migrante clandestino no processo de produção industrial de carne: a sequência inicial é construída como uma publicidade para a multinacional em questão, mas um lento movimento ótico em direção a um pedaço de carne grelhada leva o recetor a entender que em parte o filme "dissecará" o processo que leva a carne ao consumidor. A esta segue-se uma segunda sequência (fronteira México-Estado Unidos, exterior noturno) que introduz o grupo de migrantes prestes a encetar a sua viagem. A montagem alternada opera assim a junção entre o mundo dos clandestinos e o mundo do talho industrial, e justamente porque se trata deste tipo de montagem o recetor entende o propósito de Linklater: apontar para a indissociabilidade de ambos os mundos em certos setores da economia neoliberal.

Não será por acaso que, durante a sua visita de controlo ao talho industrial onde trabalham os migrantes (00:26:13 - 00:28:30), Anderson, encarregado de entender a origem da presença de matéria fecal na carne bovina, somente esteja interessado nas condições materiais em que esta se produz (higiene, limpeza das máquinas, etc.), sem prestar atenção ao estatuto dos trabalhadores migrantes presentes ao longo da linha de produção. Literalmente passa ao lado destes, e da sua constante exploração. A sequência acaba com o grupo a assistir a um programa de prevenção dos acidentes de trabalho. Don passa em frente ao grupo sem parar, como se estes ocupassem um lugar natural no cenário em questão.

A presença da personagem de Anderson, homem maduro, mergulhado numa espécie de crise por causa do que vai descobrindo a propósito da produção industrial de carne, permite-me focar outra característica da fronteira encenada pelos filmes do corpus: a presença na fronteira de um cidadão ocidental em crise junto ao migrante clandestino.

\section{O intermediário necessário na fronteira: o homem ocidental de meia-idade em crise}

Em certos filmes do corpus, o migrante ilegal partilha o guião com outra personagem, a do homem ocidental de meia-idade em crise (por causa de um divórcio ou da morte da esposa), que reencontra um certo alento pelo 
contacto com o migrante clandestino. Tanto Simon em Welcome como Walter em The Visitor serão, em determinada altura, confrontados com o Outro, sujeito sem documentos, ser fronteiriço à espera de passar para o lado da fronteira onde se é cidadão. Assim, Walter, até ao encontro com Tarek e Zainab, o casal que ocupa o seu apartamento em Nova Iorque, aparece quase exclusivamente em sequências de interior: dentro de casa, no seu gabinete, no carro e sempre filmado em plano americano ou em plano aproximado. A escala de plano é aqui muito significativa pois serve, por um lado, para analisar o rosto da personagem principal e, por outro lado, para insistir na sensação de fechamento. Não seria errado ver nestes tipos de plano uma metáfora do estilo de vida levada por Walter.

Há claramente uma dicotomia que atravessa - ou melhor que estrutura The Visitor entre o dentro (associado ao tédio) e o fora (associado à vida) quando Walter se depara com jovens músicos a tocar em baldes de plástico num parque de Nova Iorque. É fora da Universidade que Walter sente o ritmo, experimenta a pulsação da vida. A seguir, passa um colega que o convida para voltar para dentro. Só que, a partir de agora, o dentro (tanto a vida íntima de Walter como a sua casa) nunca mais será o mesmo. Encontra-se esta mudança ilustrada na sequência da primeira aula de jembê de Walter com Tarek (00:22:57 -00:26:26). Se, no início do filme, Walter tocava piano em casa sozinho na penumbra, agora, numa escala de plano idêntica, temos um Walter em plena luz e sorridente. O plano de semiconjunto aqui já não realça a solidão de Walter, mas torna-se cinematograficamente necessário para, por um lado, mostrar a luz a iluminar o cenário e, por outro lado, deixar espaço para Tarek. Existe outra sequência paradigmática neste contexto: depois do concerto dado no parque, Tarek e Walter caminham juntos em plano americano a meia-perna; aos poucos um movimento ótico transforma a escala de plano até acabar em plano de grande conjunto mostrando o parque, as pessoas, a cidade e, por fim, a luz radiante. Parece que a felicidade de Walter cresce de forma proporcional ao movimento ótico.

É de relevar, ainda que de passagem, que este Outro representado como a salvação da personagem em crise também se manifesta em filmes onde o migrante e os seus filhos vivem legalmente no país de referência. É o que acontece em Gran Torino (Eastwood, 2008), no qual a personagem de Walt Kowalski, interpretada por um Eastwood crepuscular, consegue reorientar a sua vida e dar significado à sua morte no contacto com os seus vizinhos Hmong em geral e o jovem Thao em particular (Thao sendo o equivalente deste lado da fronteira a Tarek e Bilal, vindos do outro lado). Este filme não para de evidenciar fronteiras, umas visíveis, outras menos, umas de ordem pública, outras de ordem mais privada, assim como múltiplas transgressões das mesmas. 
Pode dizer-se que existe uma espécie de linha invisível que separa Walt dos seus vizinhos, os limites da sua propriedade correspondendo a uma fronteira cultural, intransponível durante parte do filme. Do ponto de vista de Kowalski, deste lado da fronteira ter-se-ia a "civilização" (a língua inglesa, a bandeira americana, o relvado cortado, a casa em perfeito estado) e, do outro lado da fronteira, o que ele considera "os bárbaros" (uma língua diferente, um relvado ao abandono, uma casa em mau estado). Este outro lado é-lhe desconhecido e os Hmong equivalem, na sua representação do mundo, aos coreanos, chineses, em suma, aos asiáticos em geral. Note-se de passagem que, do outro lado, Walt tem uma equivalente: a avó, também num primeiro momento relutante em ter um vizinho americano, branco (vejam a sequência na qual lhe pergunta em Hmong porque ainda não deixou o bairro). O recetor percebe que Kowalski muda quando as personagens começam a circular através da fronteira, quando há fluidez e movimentos entre os espaços, ou seja, quando Walt aceita, por um lado, cruzar a fronteira para partilhar um almoço Hmong e, por outro lado, quando aceita Thao, como ajudante, no seu espaço privado.

Estas múltiplas passagens de fronteira evidenciam a possibilidade de mobilidade entre os dois lados, apesar das representações em vigor de cada um dos lados. Por sua vez, a mobilidade revela um mundo em plena mudança. É a própria sociedade americana - como qualquer outra sociedade ocidental - que se depara com a chegada de novos imigrantes (com a desconfiança $\mathrm{e}$, às vezes, o medo que se sente de ambos os lados). Uma curta sequência é muito reveladora desta situação: a da consulta de Walt no hospital. Na sala de espera, a personagem observa os outros utentes e constata que muitos são de origem estrangeira assim como a enfermeira, a nova médica... O mundo de Walt está a transformar-se de maneira rápida, talvez de maneira mais rápida do que em qualquer outro momento da história do seu mundo.

Se alguém nestes filmes experimenta positivamente o que acontece neste contexto fronteiriço é a personagem recorrente do homem ocidental em plena crise existencial. Ao contacto com o Outro, Walter, Simon e Walt afastam-se das origens da sua infelicidade e, por assim dizer, encetam uma viagem interna que os leva a redefinir a sua identidade. A fronteira torna-se então um lugar de hibridação e de salvação para um cidadão (oriundo do Norte) sem rumo, mas não para um sujeito (oriundo do Sul) à procura de um porto seguro.

Lembrar-se-á que a hibridação como limite experimentado na "fronteira" se encontra em grande parte celebrada nos textos de Ribeiro e Santos. Para o primeiro, seria difícil pensar identidades híbridas ou mestiças sem "fronteiras", pois radica na "fronteira" o que fundamenta este tipo de subjetividade: 
a plurivocidade, a ambiguidade, a heterogeneidade. É consciente das tensões e relações desiguais de poder inerentes às identidades híbridas que Ribeiro estuda o fenómeno fronteiriço. $\mathrm{Na}$ sua conceção, a "fronteira" não tem delimitação clara, ou seja, o autor recusa "a noção de que a 'linha' de fronteira define rigidamente uma binaridade entre um dentro e um fora, o totalmente familiar e o inteiramente estranho, não consentindo, assim, qualquer modo de mediação ou de articulação" (Ribeiro, 2001: 471). O que propõe relativamente à sociabilidade na fronteira recorda o que acontece a certas personagens na sua equivalente ficcional: "A fronteira é um medium de comunicação, o espaço habitável em que o eu e o outro encontram uma possibilidade de partilha e, assim, a possibilidade de dar origem a novas configurações de identidade" (ibidem).

Se os realizadores destes três filmes escolheram uma estética da ilusão, uma total legibilidade, a presença de um intermediário com o qual o recetor se possa identificar, tal se deve em grande parte à vontade de convencer/seduzir o público ocidental (e de facto Gran Torino, The Visitor e Welcome foram sucessos de bilheteira). Outros filmes como Le silence de Lorna, Promised Land, Transe ou Lilya 4ever caracterizam-se por uma estética marcada pela alusão, a tradução da evolução das personagens migrantes através de metáforas, a ausência do intermediário. Todos colocam a questão do olhar do recetor na fronteira: como ver o/a migrante ilegal e, a fortiori, como olhar para o corpo da mulher traficada na fronteira (como é o caso nos três últimos).

\section{Importância do ponto de vista do recetor}

A questão da instância de receção e da sua relação com a diegese, têm sido uma preocupação teórica para os analistas de filmes: quem recebe o filme e de que maneira? Como apontam análises fílmicas recentes (e.g. Garraio, 2011), não se pode de facto evitar questionar o lugar do recetor nas ficções que nos ocupam aqui, nomeadamente o olhar do recetor relativamente ao corpo das mulheres traficadas. O olhar do espetador, o seu ponto de vista, parece deste modo indispensável à representação do/a migrante clandestino na fronteira, pois cada filme, independentemente das suas escolhas estéticas, envolve o recetor.

A estética dos filmes depende em parte desta questão inicial: o que fazer com os corpos violentados na fronteira? Representá-los no campo ou no fora de campo? São as respostas a estas questões que levaram Gitai, Villaverde e Moodysson a optar por certas escolhas estéticas. Em Promised Land, o realizador israelita escolheu filmar com câmaras digitais para reforçar o efeito de real. Além disso, em virtude das suas características técnicas (máquinas pequenas e leves), conseguiu seguir as personagens 
de perto, colar-se aos seus passos. ${ }^{7}$ A sequência da venda das mulheres no deserto ilustra paradigmaticamente a relação entre escolha técnica, estética e significado: a câmara circula entre os corpos, observa-os como se de um traficante se tratasse, ou seja, aqui o recetor encontra-se, com o recurso à câmara subjetiva, a observar os corpos como se fosse um traficante entre os outros, daí sem dúvida a sensação de incómodo criada junto da instância de receção. Mais à frente, no momento em que as mulheres passam o checkpoint levadas pelos traficantes, vários transeuntes anónimos olham diretamente para a objetiva. Aqui, o realizador não escondeu a máquina de filmar, transgredindo as fronteiras entre ficção e documentário - neste género cinematográfico o olhar-câmara e a presença assumida da máquina de filmar fazem parte dos códigos -, o que leva agora o espetador a sentir-se observado. Talvez seja nesta passagem do recetor do estatuto de observador ao de observado que radica a articulação entre estética, ponto de vista e ética, pois Gitai obriga assim o espetador a questionar não a prostituição forçada (esta é condenada à partida), mas sim os valores e a moral do sistema socioeconómico no qual se insere total ou parcialmente.

Lilya 4ever e Transe colocaram igualmente a questão do olhar do recetor no centro das suas preocupações, se bem que com dispositivos diferentes. O primeiro coloca o espetador numa situação desconfortável ao confrontá-lo com a violência sexual contra a personagem principal pelo recurso à câmara subjetiva: uma sequência composta por uma sucessão rápida de planos em montagem cut-cut mostra a cara dos clientes em cima da vítima, ou seja, neste caso a instância de receção confunde-se nitidamente com o olhar desta. Mais uma vez a escolha estética tem claras implicações éticas. ${ }^{8}$ Em Transe, de certo modo o filme mais complexo, e talvez o menos acessível do corpus, a realizadora portuguesa interroga constantemente o olhar do espetador, colocando-o em cena em certos momentos. Assim, uma sequência que se situa depois da violação de Sonia pelo seu raptor russo encena, num plano fixo, Sonia nua em pano de fundo a vestir-se e, na frente esquerda, as costas do violador em plano aproximado a observar o corpo da primeira (00:55:09). Nesta configuração inicial do espaço fílmico, o olhar da instância de receção duplica o do violador, o que por si já torna o lugar

\footnotetext{
${ }_{7}$ Eis o que Gitai afirmava a este propósito: "Queria que a passagem de um lugar ao outro fosse muito fluída. Queria também captar as nuances das relações entre as personagens. Era preciso portanto elaborar uma estratégia de filmagem próxima do direto. Graças a estas pequenas câmaras digitais pudemos aproximar-nos bastante e dar ao filme essa sensação de proximidade. É este lado bruto que permite criar a sensação de urgência. A câmara estava sempre pronta a captar a sensibilidade à flor da pele, isso fascinou-me." (Gitai apud Garraio, 2011).

${ }^{8}$ É de notar que Lilya 4ever tem sido utilizado por ONG para sensibilizar certos públicos em relação à questão do tráfico de mulheres para exploração sexual (Garraio, 2011).
} 
da primeira incomodativo, mas, no momento em que o violador se deita e para de olhar, a situação do espetador torna-se quase impossível, pois, neste momento preciso, já não existe intermediário entre aquele corpo e o "eu-espetador" a observá-lo. De maneira radical, Villaverde encarcera o espetador numa espécie de duplo constrangimento: recusar a posição de voyeur, o que o levaria eventualmente a parar de ver o filme, ou questionar incessantemente o nosso ponto de vista sobre o corpo sofredor. Em ambos os casos, o espetador encontra-se numa situação complexa, que incomoda, a meio-caminho entre cumplicidade e distanciamento crítico.

Por fim, em Fast Food Nation, o recetor é o único que tem acesso ao conjunto das informações, que segue ao mesmo tempo Don na sua investigação e o grupo de migrantes na sua procura de uma vida melhor. Por exemplo, este é o único a saber o que acontece ao migrante anónimo que se afastou do grupo em pleno deserto e que ali morre. Nesta posição de surplomb, a instância de receção é a única a perceber que, embora Anderson e os mexicanos nunca venham a comunicar, as suas rotas estão intimamente ligadas. Veja-se, por exemplo, a curta sequência em que Don no seu carro e os migrantes escondidos numa carrinha param lado a lado num cruzamento (00:15:37), lugar simbólico de encontro e de separação. O espetador entende aqui que, embora nunca entrem em contacto na diegese, as personagens são indissociáveis no sistema económico-social representado.

\section{Conclusão}

Podemos assim entender as razões que levaram os realizadores a focar quase exclusivamente um tipo de migrante - o "ilegal" - em detrimento de outros. Talvez justamente porque o clandestino, por um lado, agregue os sofrimentos decorrentes de uma vida na fronteira e, por outro lado, simbolize paradigmaticamente as consequências negativas das assimetrias induzidas pela organização neoliberal da economia. Como vimos, os filmes representam os migrantes clandestinos no momento em que se preparam para atravessar a fronteira física entre o Sul e o Norte ou já do outro lado da fronteira, à procura de uma vida diferente. Independentemente do lugar ocupado pela personagem do/a migrante, esta experimenta a fronteira e os seus efeitos, negativos na maior parte dos casos. Sabemos agora que este tipo de sociabilidade emerge bem antes da chegada do sujeito à fronteira física entre dois Estados. Neste ponto, é de sublinhar que estas ficções tendem a sediar a origem geográfica destas experiências fronteiriças em territórios sob controlo de forças policiais ocidentais (europeias ou norte-americanas), nomeadamente nos centros de retenção para migrantes "ilegais" (cf. o meu comentário a Welcome, neste volume, pp. 147-179). Porém, os efeitos negativos 
de uma sociabilidade na fronteira para o migrante clandestino começam em muitos casos bem antes da sua chegada a um destes campos. Cada vez mais aliás, por causa da delegação do controlo das fronteiras externas da União Europeia a certos Estados do Magrebe (Conselho Europeu de Sevilha, junho de 2002), esta sociabilidade vive-se dolorosamente em centros de detenção sediados no Sul, nomeadamente em Marrocos (Boukhari, 2007).

Gostaria finalmente de apontar ainda para a complementaridade entre ciências sociais e humanas em análises deste tipo. No caso presente não se procedeu nem a uma análise fílmica interna, nem à leitura do filme como um documento semelhante a qualquer outro documento. Pelo contrário, mostrou-se em vários momentos que, se um filme dimana do social, fá-lo com recurso a figuras de retórica, a personagens, a configurações narrativas que dizem o social de um modo peculiar. Quiçá seja na fronteira, mais uma, entre as ciências que este peculiar melhor se revela. ${ }^{9}$

\section{Referências bibliográficas}

Bauman, Zygmunt (2004), Wasted Lives. Modernity and its Outcasts. Cambridge \& Malden: Polity Press.

Bauman, Zygmunt (2007), Liquid Times. Living in an Age of Uncertainty. Cambridge \& Malden: Polity Press.

Bennafla, Karine; Peraldi, Michel (2008), "Frontières et logiques de passage: l'ordinaire des transgressions", Cultures \& Conflits, 72. Consultado a 21.06.2009, em www. conflits.org/index $17383 . \mathrm{html}$.

Boukhari, Sophie (2007), "La longue traque des migrants clandestins au Maroc", Le Monde diplomatique, maio, n. ${ }^{\circ}$ 638, pp.16-17.

Darley, Mathilde (2008), "Le contrôle migratoire aux frontières Schengen: pratiques et représentations des polices sur la ligne tchéco-autrichienne”, Cultures \& Conflits, 71. Consultado a 22.06.2009, em www.conflits.org/index16583.html.

Fassin, Eric (2009), "L'immigration, un 'problème' si commode", Le Monde diplomatique, novembro, n. ${ }^{\circ} 668$, p. 22.

Garraio, Júlia (2011), "Prostituição forçada de migrantes de Leste no cinema europeu contemporâneo", e-cadernos CES, 14, 77-102. Consultado a 03.11.2014, em http:// eces.revues.org/897.

Guez, Sabine (2008), "La frontière et au-delà. Une enquête ethnographique sur le narcotrafic à Ciudad Juarez (Mexique) et El Paso (États-Unis)", Cultures \& Conflits, 72. Consultado a 21.06.2009, em www.conflits.org/index17383.html.

\footnotetext{
${ }^{9}$ Esta articulação entre ciências revela ainda o quão essencial são as humanidades para a compreensão do nosso mundo (neste ponto remeto para o artigo "Humanidades" de António Sousa Ribeiro no Dicionário das Crises e das Alternativas, 2012, CES/Almedina).
} 
Mandelbaum, Jacques; Ridet, Philippe (2011), "L’immigré, vedette américaine de la Mostra de Venise", Le Monde, 11-12 de setembro, p. 18.

Mandelbaum, Jacques; Sotinel, Thomas (2009), "La figure de l'immigrant clandestin au cinéma”, Le Monde, 28 de março. Consultado a 20.11.2011, em http://www. lemonde.fr.

Makaremi, Chowra (2008), "Pénalisation de la circulation et reconfigurations de la frontière: le maintien des étrangers en zone d'attente”, Cultures \& Conflits, 71. Consultado a 22.06.2009, em www.conflits.org/index16133.html.

Nasraoui, Mustapha (2013), Le migrant clandestin. Le paradoxe de l'être et de la société. Paris: L'Harmattan.

PNUD (2009), Rapport mondial sur le développement bumain. Lever les barrières : mobilité et développement bumains. New York: Programme des Nations Unies pour le développement.

Ribeiro, António Sousa (2001), "A retórica dos limites. Notas sobre o conceito de fronteira”, in Boaventura de Sousa Santos (org.), Globalização. Fatalidade ou utopia? Porto: Afrontamento, 463-488.

Rush, Elisabeth (2012), “Inde-Bangladesh, la frontière déjouée”, Le Monde diplomatique, agosto, n. ${ }^{\circ}$ 701, pp.6-7.

Santos, Boaventura de Sousa (2000), A crítica da razão indolente. Contra o desperdício da experiência. Porto: Afrontamento.

Sassen, Saskia (2002), "Será este o caminho? Como lidar com a imigração na era da globalização”, Revista Crítica de Ciências Sociais, 64, 41-54.

Sotinel, Thomas (2009), "Le maître-nageur dans le grand bain des migrants", Le Monde, 11 de março. Consultado a 11.09.2011, em http://www.lemonde.fr.

Vigna, Anne (2008), "Le jour où le Mexique fut privé de tortillas”, Le Monde diplomatique, março, n. ${ }^{\circ} 648$, pp. 8-9.

Vigna, Anne (2009), “A Tijuana, la mauvaise fortune des maquiladoras”, Le Monde diplomatique, novembro, n. ${ }^{\circ} 668$, pp. 18-19.

Artigo recebido a 08.02.2014

Aprovado para publicação a 03.11.2014

\section{Fabrice Schurmans}

Centro de Estudos Sociais, Universidade de Coimbra

Colégio de S. Jerónimo, Largo D. Dinis, Apartado 3087, 3000-995 Coimbra, Portugal

Contacto: fschurmans@yahoo.fr 
